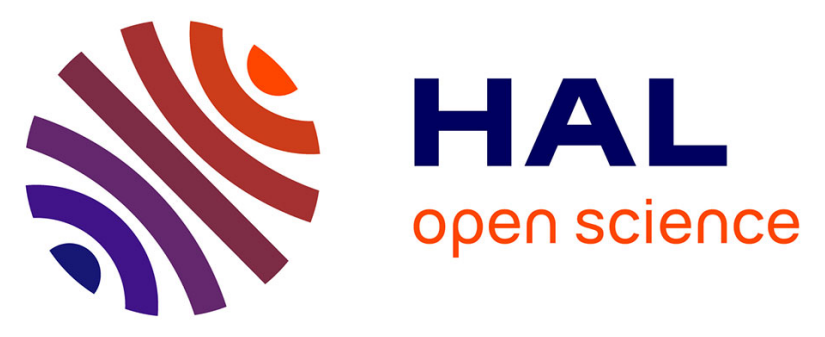

\title{
Mycobacterial Ser/Thr protein kinases and phosphatases: physiological roles and therapeutic potential.
}

Annemarie Wehenkel, Marco Bellinzoni, Martin Graña, Rosario Duran, Andrea Villarino, Pablo Fernandez, Gwenaëlle André-Leroux, Patrick England, Howard Takiff, Carlos Cerveñansky, et al.

\section{To cite this version:}

Annemarie Wehenkel, Marco Bellinzoni, Martin Graña, Rosario Duran, Andrea Villarino, et al.. Mycobacterial Ser/Thr protein kinases and phosphatases: physiological roles and therapeutic potential.. Biochimica et Biophysica Acta - Molecular Cell Research, 2008, 1784 (1), pp.193-202. 10.1016/j.bbapap.2007.08.006 . pasteur-00508942

\section{HAL Id: pasteur-00508942 \\ https://hal-riip.archives-ouvertes.fr/pasteur-00508942}

Submitted on 31 May 2020

HAL is a multi-disciplinary open access archive for the deposit and dissemination of scientific research documents, whether they are published or not. The documents may come from teaching and research institutions in France or abroad, or from public or private research centers.
L'archive ouverte pluridisciplinaire HAL, est destinée au dépôt et à la diffusion de documents scientifiques de niveau recherche, publiés ou non, émanant des établissements d'enseignement et de recherche français ou étrangers, des laboratoires publics ou privés. 


\title{
Review
}

\section{Mycobacterial Ser/Thr protein kinases and phosphatases: Physiological roles and therapeutic potential}

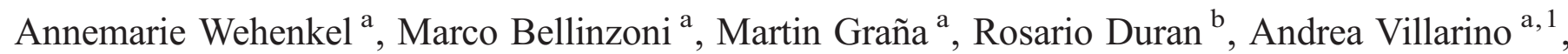 \\ Pablo Fernandez ${ }^{\text {a, }}$, Gwénaëlle Andre-Leroux ${ }^{a}$, Patrick England ${ }^{\text {a }}$, Howard Takiff ${ }^{\text {a, } 3}$, \\ Carlos Cerveñansky ${ }^{\mathrm{b}}$, Stewart T. Cole ${ }^{\mathrm{c}, 4}$, Pedro M. Alzari ${ }^{\mathrm{a}, *}$ \\ ${ }^{a}$ Unité de Biochimie Structurale, URA 2185 CNRS, Institut Pasteur, 25 rue du Docteur Roux, F-75724 Paris Cedex 15, France \\ ${ }^{\mathrm{b}}$ Unidad de Bioquimica y Proteomica Analiticas-IIBCE, Institut Pasteur de Montevideo, Mataojo 2020, Montevideo, Uruguay \\ ${ }^{\mathrm{c}}$ Unité de Génétique Moléculaire Bactérienne, Institut Pasteur, 28 rue du Docteur Roux, 75724 Paris, France
}

Received 25 July 2007; received in revised form 1 August 2007; accepted 3 August 2007

Available online 14 August 2007

\begin{abstract}
Reversible protein phosphorylation is a major regulation mechanism of fundamental biological processes, not only in eukaryotes but also in bacteria. A growing body of evidence suggests that Ser/Thr phosphorylation play important roles in the physiology and virulence of Mycobacterium tuberculosis, the etiological agent of tuberculosis. This pathogen uses 'eukaryotic-like' Ser/Thr protein kinases and phosphatases not only to regulate many intracellular metabolic processes, but also to interfere with signaling pathways of the infected host cell. Disrupting such processes by means of selective inhibitors may thus provide new pharmaceutical weapons to combat the disease. Here we review the current knowledge on Ser/Thr protein kinases and phosphatases in M. tuberculosis, their regulation mechanisms and putative substrates, and we explore their therapeutic potential as possible targets for the development of new anti-mycobacterial compounds.
\end{abstract}

(C) 2007 Elsevier B.V. All rights reserved.

Keywords: Mycobacterium tuberculosis; Ser/Thr protein phosphorylation; Protein kinases; Protein phosphatases; Drug design

\section{Introduction}

Mycobacterium tuberculosis is the causative agent of tuberculosis, a major health problem worldwide that is responsible for the deaths of over two million people every year. A better understanding of the physiopathology of the tubercle bacillus, with the goal of discovering and validating new therapeutic targets, is an imperative need to improve the treatment of tuberculosis. Emerging evidence suggests that signaling elements, in particular those involved in Ser/Thr protein phosphorylation, may represent a new class of promising targets. Recent studies are starting to unveil the important roles of Ser/Thr protein kinases (STPKs) and phosphatases in mycobacterial physiology and virulence. Furthermore, the low sequence identities $(<30 \%)$ between mycobacterial and human STPKs, and the expertise available in the design of specific inhibitors for eukaryotic STPKs, currently one of the most active therapeutic areas [1], may be exploited to develop novel antibiotics targeting this enzyme family in mycobacteria.

Abbreviations: STPK, Ser/Thr protein kinase; FHA, forkhead-associated domain; PASTA, penicillin-binding protein and Ser/Thr kinase-associated domain; PTP, protein tyrosine kinase; pThr, phospho-threonine; pSer, phospho-serine; MS, mass spectrometry

* Corresponding author. Tel.: +33 1 45688607; fax: +33 145688604 .

E-mail address: alzari@pasteur.fr (P.M. Alzari).

${ }^{1}$ Current address: Centro de Biologia Molecular Estrutural-UFSC, Departamento de Bioquímica, CCB UFSC, 88040900 Florianópolis, Brazil.

${ }^{2}$ Current address: Unité de Biologie des Interactions Hôte-Parasite, Institut Pasteur, Paris, France.

${ }^{3}$ Current address: Lab. De Genética Molecular, CMBC-IVIC, Caracas, Venezuela.

${ }^{4}$ Current address: Global Health Institute, EPFL, Lausanne, Switzerland. 
The initial analysis of predicted protein kinases in $M$. tuberculosis was described by Av-Gay and co-workers [2] and an excellent review on current structure/function studies of Ser/ Thr and Tyr protein phosphorylation has been published recently by Alber and co-workers [3]. Here, we will focus on the physiological properties and therapeutic potential of mycobacterial Ser/Thr protein kinases and phosphatases as deduced from recent genetic, biochemical and structural studies.

\section{Signaling mechanisms in prokaryotes}

Signal transduction involving reversible protein phosphorylation in prokaryotes is primarily conducted by two-component systems. In their simplest form, these systems consist of a sensor histidine kinase and a response regulator [4], although signaling cascades involving several histidine kinases and/or response regulators may function in a phospho-relay mechanism to control complex developmental processes such as sporulation $[5,6]$ and [7]. The availability of complete genome sequences has confirmed the prevalence of two-component systems in bacteria. Although the number of these proteins differs greatly (ranging from none in Mycoplasma genitalium, [8] and [9], to 80 in Synechocystis sp. [10]), the genes coding for two-component systems typically represent $1-2 \%$ of the bacterial genome (Fig. 1). The M. tuberculosis genome encodes 11 complete twocomponent systems, several of which contribute to the virulence of M. tuberculosis [11-14] and [15], but only one system (MtrA, MtrB) was reported to be essential for cell growth [16].

Interestingly, mycobacterial genomes contain a relatively low number of two-component systems when compared to other bacterial genomes of similar size. This reduced number of histidine kinases and response regulators appears to be offset by alternative signal transduction mechanisms involving Ser/Thr phosphorylation (Fig. 1). Indeed, the M. tuberculosis genome has as many genes coding for STPKs as those coding for complete two-component systems $[17,18]$ and [19]. Other mycobacterial genomes have an even greater number of STPK genes (24 in the Mycobacterium marinum genome [20]), suggesting that Ser/Thr phosphorylation mediates the bulk of signal transduction.

\section{The eukaryotic-like protein kinases in M. tuberculosis}

The M. tuberculosis genome includes 11 STPK genes, namely $p k n A$ to $p k n L$ [17], and their domain organization indicates that only two enzymes (PknG and PknK) are soluble proteins. All other mycobacterial STPKs are predicted to be transmembrane (receptor-like) proteins [2], with their Nterminal kinase domain connected through a single transmembrane helix to one or more C-terminal domains that presumably serve as signal sensors.

The catalytic domains of all mycobacterial STPKs include the 12 conserved motifs defining the 'signature' of eukaryotic protein kinases [2] and [21]. The comparative sequence analysis of the mycobacterial kinase domains with those of other prokaryotic STPKs shows that they can be grouped in welldefined homology clusters (Fig. 2A). Thus, the nine $M$. tuberculosis receptor-like STPKs belong to three distinct groups (PknA/PknB/PknL, PknF/PknI/PknJ and PknD/PknE/PknH), while the two soluble enzymes (PknG and PknK) stand clearly apart from all the others [20]. Despite these differences, however, bacterial STPK sequences are more similar to each other than to their human homologues, with which they share less than 30\% sequence identity. A distance tree (Fig. 2B) shows

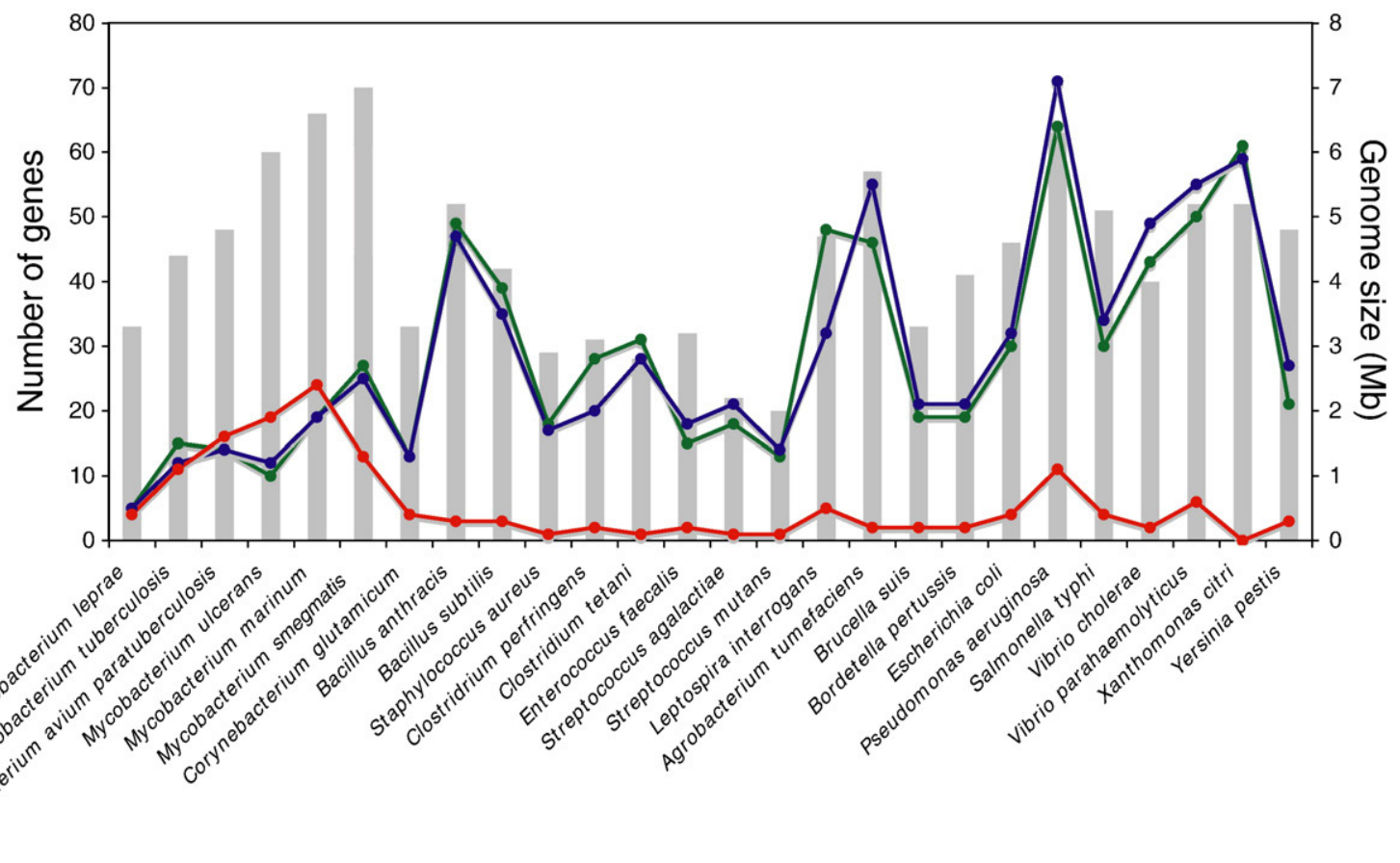

Fig. 1. Signaling elements in bacteria. The figure shows genome sizes in Mb (grey bars) and the number of genes encoding two-component systems (His kinases, blue dots; response regulators, green dots) and STPKs (red dots), as defined by homology searches in selected bacterial genomes. 
that M. tuberculosis STPKs form a separate cluster closer to but distinct from - the CK1 (casein kinase 1) group of human kinases, as defined by Manning and co-workers [22]. This low similarity is particularly relevant for drug design, as it can be exploited to increase the selectivity of antimycobacterial compounds targeting the STPKs.

\subsection{Crystal structures of the catalytic domains. Insights into kinase regulation}

The crystallographic studies of the kinase domain of $\mathrm{PknB}$ in complex with ATP analogues yielded the first structure of a bacterial STPK [23] and [24] and confirmed the remarkable conservation of the overall protein fold and catalytic machinery between eukaryotic and prokaryotic STPKs (Fig. 3A). However, unlike many eukaryotic STPKs, the activation loop of PknB, having at least two fully phosphorylated threonine residues (Thr171 and Thr173) [24] and [25], was found to be disordered in the available structures, suggesting an induced-fit mode of binding for the acceptor substrate(s) or other modulating factors. On the other hand, the phosphorylation state of this loop was shown to regulate kinase activity, in much the same way as their eukaryotic counterparts, because dephosphorylation of PknB by the cognate Ser/Thr protein phosphatase, PstP, or mutation of the autophosphorylation sites Thr171 and Thr173, significantly decreased kinase activity [25].

Alber and co-workers [3] and [24] noted that bacterial PknBlike STPKs have a conserved site on the opposite side of the Nterminal lobe relative to the active site, which might be functionally important. This conserved surface forms the dimerization interface in three independent crystal forms of $\mathrm{PknB}[23,24]$ and [26] and the equivalent region was also involved in dimerization of the PknE structure [27]. Furthermore, the formation of a very similar 'back-to-back' dimer was recently shown to activate the RNA-dependent antiviral protein kinase PKR [28] and [29], suggesting that mycobacterial enzymes use an analogous mechanism of regulation [26]. According to this model, monomeric $\mathrm{PknB}$ would be inactive due for instance to a misplacement of helix $\alpha \mathrm{C}$, whose $\mathrm{C}$ terminal end contributes to the dimer interface. Ligand binding to the extracellular sensor domain would then promote 'back-toback' dimerization of the kinase domain and subsequent activation. A direct effect of the extracellular domain on kinase dimerization was indeed demonstrated for the PknB-like protein kinase PrkC from Bacillus subtilis [30], and recent work on M. tuberculosis PknD has confirmed the major features of this model, demonstrating that dimer formation allosterically activates the kinase in vitro [31]. Interestingly, the dimer interface is well conserved within each clade of receptor-like kinases (PknA/PknB/PknL, PknF/PknI/PknJ and PknH/PknE/ $\mathrm{PknD}$ ) [20], suggesting the possibility of hierarchical signaling networks regulated by ligand-induced heterodimer formation [31].

\subsection{The extracellular 'sensor' domains of receptor-like STPKs}

The functional properties of the putative sensor domains from transmembrane STPKs remain poorly understood. The extracellular domain of PknD has been structurally characterized and found to fold into a highly symmetric six-bladed $\beta$ propeller [32]. The authors suggested that $P \mathrm{knD}$ could bind a multivalent ligand that signals by changing the quaternary structure of the intracellular kinase domain, although the structure failed to provide strong clues about the nature of the
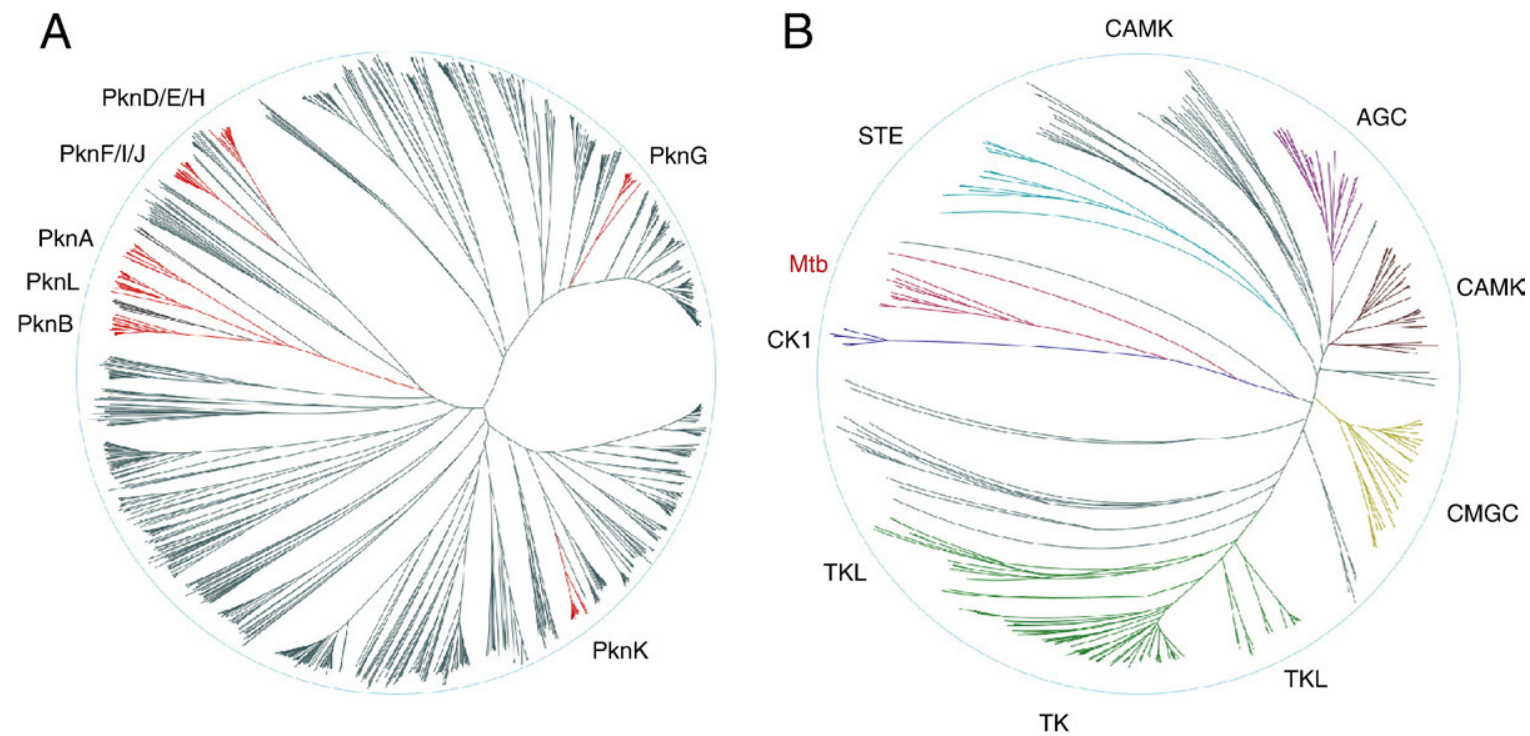

Fig. 2. Dendograms of a multiple sequence comparison of kinase domains. (A) Distance tree of 1311 prokaryotic STPKs identified from sequence homology searches using hidden Markov models for profile analysis [100]. M. tuberculosis STPKs and closely related sequences are shown in red and labeled. (B) Distance tree of all mycobacterial STPKs (Mtb, in red) and human STPKs representative of the different groups proposed by Manning and co-workers [22] (AGC, containing PKA, PKG, PKC families; $C A M K$, calcium/calmodulin-dependent protein kinases; $C K 1$, casein kinase 1; CMGC, containing CDK, MAPK, GSK3, CLK families; STE, homologs of yeast Sterile 7, Sterile 11, Sterile 20 kinases; TK, tyrosine kinases; TKL, tyrosine kinase-like). 

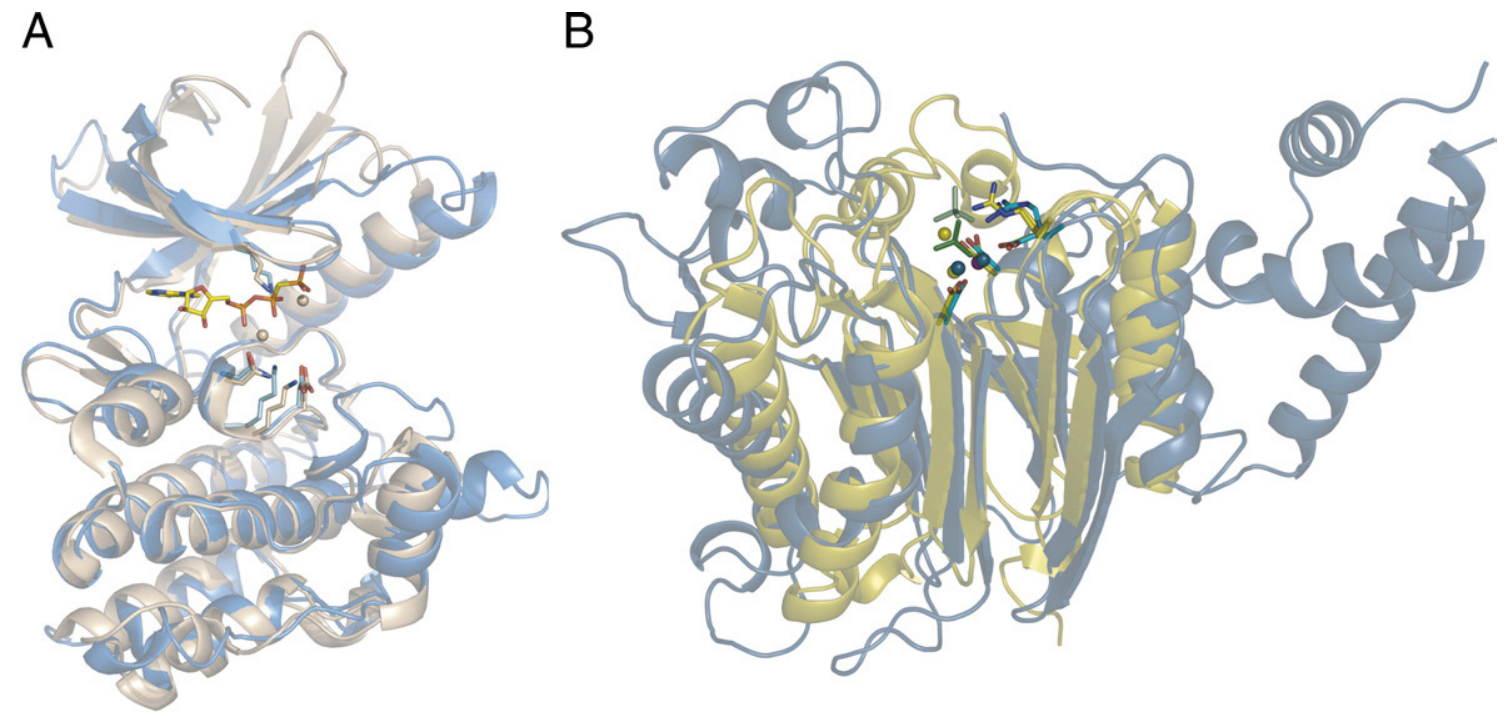

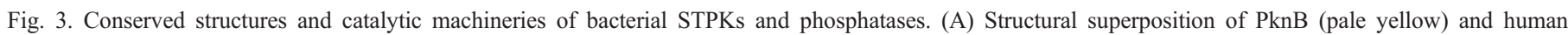

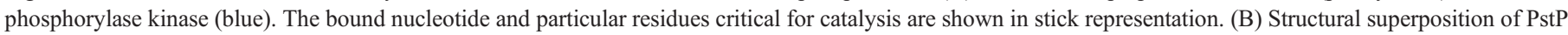

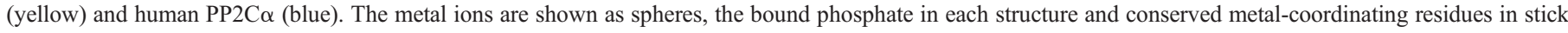
representation.

regulatory ligand(s) [32]. Other STPK sensor domains have yet to be characterized experimentally. In the case of PknB, the Cterminal domain consists of four repeated PASTA domains (named for Penicillin-binding protein And Serine/Threonine kinase Associated) [24] and [25]. These small domains are frequently found in bacterial STPKs and high molecular weight penicillin-binding proteins [33]. A possible clue to their function came from the structure of the penicillin-binding protein $2 \mathrm{x}(\mathrm{Pbp} 2 \mathrm{x})$ from Streptococcus pneumoniae, which contains two PASTA domains and was found to bind the $\beta$ lactam antibiotic cefuroxime [34]. This observation led Yeats and co-workers [33] to propose that PASTA domains might specifically recognize stem-peptides from unlinked peptidoglycan, suggesting a role of STPKs in the control of peptidoglycan remodeling during cell growth [35] and the reactivation of dormant bacteria [36]. However attractive, these hypotheses remain highly speculative at this stage, not least because the peptidoglycan-binding specificity of PASTA domains has yet to be proven.

\section{The eukaryotic-like protein phosphatases in M. tuberculosis}

In addition to the STPKs, the $M$. tuberculosis genome also includes three genes ( $p s t P, p t p A, p t p B$ ) encoding eukaryotic-like protein phosphatases. PstP is a metalloenzyme that belongs to the PPM family of Ser/Thr protein phosphatases [37] and has been found to dephosphorylate various mycobacterial STPKs and their substrates [25,38] and [39]. Recent structural studies of the catalytic domain of PstP [40] and Mycobacterium smegmatis MspP (a related phosphatase lacking any transmembrane segment [41]) confirmed the conservation of the overall fold and the dinuclear metal center of mycobacterial phosphatases when compared to human $\mathrm{PP} 2 \mathrm{C} \alpha$ [42], the most representative and well-characterized member of the PPM family (Fig. 3B). However, the atomic resolution structures of MspP in complex with different ligands support an associative reaction mechanism, which differs in some important aspects from the PP $2 \mathrm{C} \alpha$ model but resembles closely that proposed for the PPP family, the second large group of eukaryotic Ser/Thr phosphatases [41]. Another major difference of bacterial PPM phosphatases with $\mathrm{PP} 2 \mathrm{C} \alpha$ is the presence of a third metal ion in the active site, first observed in PstP [40] and conserved in the structures of MspP [41] and the homologous SaSTP from Streptococcus agalactiae [43]. Recent data from our group and others suggest that this third metal is not directly involved in catalysis but could participate in substrate binding by modulating the overall conformation of the flap region $[40,41]$ and [43] (AW, MB and PMA, unpublished).

The two other eukaryotic-like phosphatases in $M$. tuberculosis, PtpA and PtpB, are secreted proteins thought to function exclusively in infected host cells, where they could interfere with unidentified signals in host signal transduction pathways, as there are no detectable tyrosine protein kinase genes in the mycobacterial genome [44] and [45]. The PtpA structure is similar to that of eukaryotic low-molecular-weight protein tyrosine phosphatases [46], while PtpB resembles the dualspecificity (Ser/Thr and Tyr) protein phosphatases [47] although it was also found to dephosphorylate phosphoinositides in vitro [48]. Disruption of the $p t p B$ gene severely impaired growth and virulence of $M$. tuberculosis in IFN- $\gamma$ activated macrophages and guinea pigs [49], suggesting possible roles of PtpB in phosphatidylinositol metabolism and/or the IFN- $\gamma$ pathway in the host [48] and [49]. Alber and co-workers [50] have developed a competitive PtpB inhibitor that showed $>60$-fold selectivity for PtpB over a panel of human PTPs, but the inhibitory effects of this compound in vivo have not been reported. 


\section{Genetic and inhibition studies of Ser/Thr protein phosphorylation in bacterial physiology and virulence}

Recent studies have started to unveil the actual involvement of Ser/Thr protein phosphorylation in bacterial physiology and virulence. Comparative genomics suggests that many STPKs may control redundant physiological processes. Indeed, only four of the eleven M. tuberculosis kinases (PknA, PknB, PknG and $\mathrm{PknL}$ ) are conserved in the close relative Mycobacterium leprae, which has undergone extensive gene decay leading to removal or inactivation of over 2,400 genes [51], as well as in Corynebacterium glutamicum, a more distantly related actinomycete [3]. In agreement with this analysis, genome-wide transposon mutagenesis suggested that most STPKs and the three phosphatases were dispensable for growth of $M$. tuberculosis in culture or in vivo, whereas only PknA, PknB and $\mathrm{PknG}$ appeared to be individually required to sustain growth in culture [52] and [53]. The effects of deleting the only recognizable Ser/Thr protein phosphatase, PstP, in $M$. tuberculosis have not been reported. However, the essentiality of one or more STPKs [52] and [54] is difficult to reconcile with the predicted non-essentiality of the pstP gene [52], suggesting that mycobacteria may produce additional Ser/Thr protein phosphatases that remain to be characterized.

Individual gene knockouts of STPK genes have partially confirmed the above results. Deletion of the $p k n D, p k n E$ and $p k n H$ genes produced no growth phenotypes in culture [55] and [56]. However, $\Delta p k n H$ strains (but not $\triangle p k n D$ or $\Delta p k n E$ ) showed a hypervirulent phenotype in mice. In samples from lung and spleen, the $\Delta p k n H$ strain grew to higher densities than the parental strain, suggesting a role of $\mathrm{PknH}$ in regulating the bacillary load in mouse organs [55]. In the case of PknF, its function was investigated by knocking down expression with antisense RNA in M. tuberculosis and by ectopic expression in M. smegmatis as a surrogate host [57]. In both cases, the authors observed changes in growth rate as well as defects in septation and cell morphology. Since the PknF gene is known to phosphorylate the ABC transporter Rv1747 [58] and [59], the effect of PknF depletion on nutrient uptake was also investigated. A significant increase of glucose uptake (but not of glycerol, leucine or oleic acid) suggests a possible involvement of $\mathrm{PknF}$ in the regulation of sugar transport [57].

\subsection{Protein kinase $P k n G$}

Since gene essentiality is an important criterion for antibacterial drug design, the above results indicate that only a few mycobacterial STPKs might represent promising therapeutic targets for the development of novel antibiotics. One of these putative targets is $\mathrm{PknG}$, whose gene was predicted to be essential by transposon insertion experiments [52]. However, the experimental data about the physiological function of this kinase are controversial. The inactivation of the $p k n G$ gene by allelic exchange in $M$. tuberculosis was first reported to decrease both the viability in vitro as well as the bacillary load in BALB/c mice, and suggested the involvement of the kinase in the regulation of intracellular glutamate/glutamine levels [60]. In contrast, the same deletion in Mycobacterium bovis BCG was independently reported to produce no growth phenotype, nor to affect glutamine uptake or intracellular amino acid concentrations [61]. Furthermore, it has been reported that deletion of $p k n G$ in the related actinobacterium C. glutamicum causes a glutamine utilization defect and the intracellular accumulation of glutamate but not glutamine, suggesting a role of PknG in the regulation of glutamate catabolism [62].

Although the physiological role of PknG inside mycobacterial cells remains unclear, the protein appears to play a key role in infection. Secretion of PknG was found to enhance mycobacterial survival within infected macrophages by inhibiting the phagosome-lysosome fusion [63]. In this work, Pieters and co-workers showed that, in contrast to the wild-type strain, M. bovis BCG lacking $\mathrm{PknG}$ is readily transferred to lysosomes and cleared from infected macrophages. Furthermore, the PknG-specific inhibitor, AX20017, increased the lysosomal localization of $M$. bovis BCG in a dose-dependent way [63]. More recent work from the same team [64] described the crystal structure of a truncated form of M. tuberculosis $\mathrm{PknG}$ in complex with AX20017. The protein has an N-terminal rubredoxin-like domain adjacent to the canonical kinase domain and a C-terminal tetratricopeptide domain involved in protein dimerization. The ATP-competitive inhibitor binds deep within a pocket shaped by a unique set of amino acid side-chains that are not found in human kinases [64]. Although the molecular mechanisms of PknG secretion, regulation and virulence are still unknown, these results demonstrate that mycobacterial STPKs that interfere with host signaling pathways can be selectively targeted to block the proliferation of $M$. tuberculosis.

\subsection{Protein kinases PknA and PknB}

The two other STPK genes ( $p k n A, p k n B)$, required for growth of $M$. tuberculosis, are found in an operon, which is highly conserved in actinobacteria [25] and [54]. This operon also includes pstP, which codes for the only recognizable Ser/Thr protein phosphatase in the genome, and the genes $\operatorname{rod} A$ and $p b p A$ encoding proteins implicated in the control of cell growth and division [65]. PbpA belongs to the family of penicillinbinding proteins, membrane proteins that play key roles in cell wall synthesis, and RodA is known to control bacterial cell shape and elongation [66] and [67]. The composition of the operon and its location near the origin of replication in actinobacteria suggests that $\mathrm{PknA}, \mathrm{PknB}$ and $\mathrm{PstP}$ could regulate processes linked to cell division and growth [2] and [54]. Indeed, the transcription of the $p k n A$ and $p k n B$ genes increases during the exponential growth phase [68] or upon infection within macrophages [69] and [70], whereas $p k n B$ expression is downregulated in a nutrient starvation model of $M$. tuberculosis persistence [71]. Ectopic expression of pknA in Escherichia coli was observed to produce an elongated cell morphology [72], and similar morphological changes were observed upon overexpression of $p k n A$ or $p k n B$ in M. smegmatis and M. bovis BCG [68], suggesting defaults in cell wall synthesis and cell division processes. Possibly linked to this phenotype, recombinant PknA 
was shown to phosphorylate and inhibit the GTPase activity of FtsZ, a protein homologous to eukaryotic tubulin, involved in septum formation [73].

Recent gene inactivation studies provided the first direct evidence that essential metabolic processes in bacterial physiology are controlled by Ser/Thr protein phosphorylation. The $p k n B$ gene in the conserved operon could only be disrupted by allelic replacement in M. tuberculosis and M. smegmatis upon the introduction of a second functional copy of the gene. Since $p k n B$ is the distal gene of the operon, the above results indicate that PknB is essential to sustain mycobacterial growth [54]. Conserved PknB-like STPKs (including the extracellular PASTA domains) are also found beyond actinobacteria, in a large number of more distantly related Gram-positive bacteria [25]. However, in contrast to mycobacteria, deletion of the $p k n B$ homologous genes in B. subtilis and Enterococcus faecalis led to no differences in growth compared with the wild-type strain [30] and [74], suggesting that bacterial pknB-like genes may be functionally unrelated, or alternatively that they have an ancient evolutionary origin, so that the biological processes under STPK control have significantly diverged in response to specific bacterial adaptation to the environment.

Prompted by the essentiality of $p k n B$ in M. tuberculosis, the effect of kinase inhibitors was tested on mycobacterial growth. ATP-competitive PknB inhibitors were found to kill different slow- and fast-growing mycobacteria (M. tuberculosis, M. smegmatis and M. aurum) with minimal inhibitory concentrations in the micromolar range [26] and [54]. Furthermore, the inhibitory effect could be partially reversed in PknB overexpressor strains of $M$. smegmatis, supporting the hypothesis that the inhibition of bacterial growth is related to $\mathrm{PknB}$ inactivation [54]. The evidence that $\mathrm{PknB}$, a structurally and mechanistically eukaryotic-like STPK, is an essential enzyme in M. tuberculosis and that $\mathrm{PknB}$ inhibitors have a significant antibacterial effect, strongly suggest that STPKs represent promising therapeutic targets for anti-tuberculosis drug design.

\section{Identification of mycobacterial STPK substrates}

Recent studies have identified a substantial number of phosphorylated proteins in bacteria, supporting the emerging view that Ser/Thr and Tyr protein phosphorylation is a general and fundamental regulatory process, not restricted to eukaryotes. Using radioactive labeling and immunostaining, 41 different phosphoproteins could be identified in the actinomycete $C$. glutamicum after in-gel digestion and mass spectrometry (MS) analysis [75]. Using a similar approach, 29 proteins were found to be phosphorylated in early stationary-phase $B$. subtilis cells [76]. More recently, Mann and co-workers [77] were able to identify 103 unique phosphopeptides from 78 B. subtilis proteins using high accuracy MS combined with biochemical enrichment of phosphopeptides from digested cell lysates. In this study, phosphorylation sites were found in several enzymes involved in the glycolytic and tricarboxylic acid cycle, as well as in kinases and members of the phosphoenolpyruvate-dependent phosphotransferase system [77]. While these initial studies provide a lower estimate for the size of the bacterial phosphoproteome, they already support the notion that STPKs regulate many metabolic processes in bacterial cells.

The identification of STPK substrates in M. tuberculosis has been the focus of many recent studies. The availability of purified catalytic domains for most kinases [25,69,72,78-81] and [82] assisted the identification of several STPK substrates in vitro. However, the physiological relevance of many of these substrates has yet to be confirmed, given the known promiscuity of STPKs [83] and the high enzyme:substrate ratios (up to 1:1) that were required to detect phosphorylation in some studies. All characterized STPKs were shown to have autophosphorylation activity. PknB was reported to contain up to four phosphorylated residues in its activation loop [24] and [25], and detailed studies of five receptor-like STPKs (PknB, PknD, PknE, PknF, PknH) revealed the presence of several autophosphorylation sites, with two recurrent clusters of $\mathrm{pThr} / \mathrm{pSer}$ residues respectively in the activation loops and juxtamembrane regions [39] and [84]. As shown for PknB and the homologous PrkC from B. subtilis, phosphorylation of the activation loop provides a mechanism of kinase regulation whereas phosphorylation of the juxtamembrane region does not appear to affect the catalytic activity [39] and [85].

Some M. tuberculosis STPKs were shown to phosphorylate in vitro a protein substrate encoded by a gene adjacent to the kinase gene. Thus, PknH was shown to phosphorylate the transcriptional regulator EmbR, PknF the Rv1747 ABC transporter and $\mathrm{PknB}$ the penicillin-binding protein $\mathrm{PbpA}$ [59,81] and [86]. Both EmbR and Rv1747 are proteins containing predicted FHA (ForkHead-Associated) domains, which are small pThr-binding protein modules involved in eukaryotic signaling pathways $[87,88]$ and [89]. The structure of M. tuberculosis EmbR in complex with a phosphopeptide confirmed that the bacterial FHA domain, which mediates the interaction of EmbR with PknH [81], binds pThr residues in a similar way as the eukaryotic proteins [90]. Extending these observations, subsequent studies reported that different FHA domain-containing proteins are substrates of various $M$. tuberculosis STPKs [91,92] and [93]. Although the physiological significance of these findings remains unclear, they suggest a web of interactions between STPKs and FHA proteins in mycobacterial signaling pathways [91].

Kremer and co-workers [94] reported that the $\beta$-ketoacyl AcpM synthases KasA and KasB, two enzymes of the fatty-acid synthase II (FAS-II) complex, are substrates of various mycobacterial STPKs in vitro. Different phosphorylation isoforms of KasA and KasB were also identified in soluble protein extracts from M. bovis BCG, suggesting that the condensing activities of the FAS-II system can be differentially regulated by phosphorylation in vivo [94]. Recent genetic studies also reported two possible physiological substrates of PknD. Phosphorylation of the cell wall fraction from a $p k n D$ knockout of a clinical M. tuberculosis isolate allowed the identification of MmpL7, which is the transporter of phthiocerol dimycocerosate, a lipid essential for virulence [56]. On the other hand, Alber and co-workers [95] reported that PknD overexpression in $M$. tuberculosis alters transcription of numerous genes. The authors showed that PknD was able to efficiently phosphorylate an anti- 
anti-sigma factor homologue, Rv0516, both in vitro and in vivo at a single N-terminal Thr residue, and that this phosphorylation inhibited the interaction of Rv0516 with a putative homologous partner, Rv2638 [95].

In a different approach, Kang et al. [68] used peptide specificity screening to find the preferred substrate motifs of $\mathrm{PknA}$ and PknB, which led them to identify two STPK substrates: Wag31, a homolog of the cell division protein DivIVA, and Rv1422, a conserved hypothetical protein. While Rv1422 was phosphorylated in vitro by both kinases, Wag31 was not phosphorylated by $\mathrm{PknB}$ and only weakly by $\mathrm{PknA}$, raising the possibility that it could be the substrate of other mycobacterial STPKs in vivo. However, Wag31 phosphorylation was enhanced when PknA and PknB acted in concert, and the expression of different alleles of the protein in vivo produced a similar cell shape phenotype to that observed for PknB overexpression [68], lending some support to the involvement of Wag31 in PknA/PknB-mediated signaling pathways.

In our laboratory, we used an unbiased proteomic approach to look for optimal substrate(s) of PknB in native cell-free extracts and culture filtrates of M. tuberculosis and M. smegmatis [92]. By optimizing the kinase assay, $\mathrm{PknB}$ was found to efficiently phosphorylate only one protein substrate, GarA (Rv1827), at a single N-terminal Thr residue. GarA (for Glycogen Accumulation Regulator) is a FHA domain-containing protein that has been proposed to play some role in the regulation of glycogen recycling during the exponential phase of $M$. smegmatis cell growth [96]. More recent work on odhI, the garA ortholog in C. glutamicum, demonstrated that OdhI inhibits the 2-oxoglutarate dehydrogenase (ODH), a key enzyme of the tricarboxylic acid cycle [62]. This inhibition is reversed upon OdhI phosphorylation by $\mathrm{PknG}$ (also at a single N-terminal Thr residue), suggesting that OdhI (GarA) could function as a phosphorylation-dependent molecular switch in the regulation of different metabolic processes.

Binding studies of PknB-GarA interactions led to a model of STPK substrate recruitment, in which the phosphorylated activation loop of PknB provides a secondary docking site for FHA-mediated substrate binding [92]. The model suggests a possible effect of substrate binding in enzyme activation and might account in part for the observation that FHA domain proteins are substrates of various STPKs with multiple autophosphorylation sites in their activation loop [39,91,92] and [93]. The PknB-GarA interaction model evokes the eukaryotic STPKs that rely on docking interactions with their substrates, using sites distinct from the active site cleft, to achieve specificity [97]. In particular, the accessibility of the activation-loop phosphates of $\mathrm{PknB}$ to engage the FHA domain is closely analogous to the SH2-mediated recruitment of the adaptor protein APS to the activated insulin receptor [98], where kinasesubstrate interactions also occur primarily via the phosphorylated activation loop.

\section{Concluding remarks}

There is a growing body of evidence to indicate that many metabolic processes in $M$. tuberculosis are regulated by STPK- mediated phosphorylation, and these range from cell wall biogenesis and cell division to central metabolic processes like the tricarboxylic acid cycle and glycogen utilization. Interfering with the signal transduction pathways governing these pathways by inhibition of the corresponding STPK activity should therefore result in marked metabolic perturbation that, in some cases, could result in cell death. Support for this notion is provided by the finding that $p k n B$, and possibly the $p k n A$ and $p k n G$ genes, are essential for cell growth.

In the past 15 years, the field of oncology has witnessed tremendous drug discovery activity with the realization that uncontrolled cell division, the cause of many human cancers and neoplasms, can be reversed or prevented by targeting the aberrant signal transduction processes with appropriate inhibitors. This has resulted in many pharmaceutical companies developing extensive libraries of compounds that block serine/ threonine and tyrosine protein kinase activity. As a result, several clinically approved anticancer drugs have been discovered and produced, such as Gleevec [99], and are now finding broad application in the treatment of life-threatening conditions, like chronic myeloid leukemia. Given the importance of tuberculosis as a global public health problem, we hope that these kinase inhibitor libraries will also be screened in order to find lead compounds for the development of new anti-TB drugs.

\section{Acknowledgements}

This work was supported by grants from the Institut Pasteur (GPH-Tuberculose) and the European Commission (NM4TB, contract LSHP-CT-2005-018923).

\section{References}

[1] P. Cohen, Protein kinases - the major drug targets of the twenty-first century? Nat. Rev. Drug Discov. 1 (2002) 309-315.

[2] Y. Av-Gay, M. Everett, The eukaryotic-like Ser/Thr protein kinases of Mycobacterium tuberculosis, Trends Microbiol. 8 (2000) 238-244.

[3] A.E. Greenstein, C. Grundner, N. Echols, L.M. Gay, T.N. Lombana, C.A. Miecskowski, K.E. Pullen, P.Y. Sung, T. Alber, Structure/function studies of Ser/Thr and Tyr protein phosphorylation in Mycobacterium tuberculosis, J. Mol. Microbiol. Biotechnol. 9 (2005) 167-181.

[4] A.M. Stock, V.L. Robinson, P.N. Goudreau, Two-component signal transduction, Ann. Rev. Biochem. 69 (2000) 183-215.

[5] P. Cashin, L. Goldsack, D. Hall, R. O'Toole, Contrasting signal transduction mechanisms in bacterial and eukaryotic gene transcription, FEMS Microbiol. Lett. 261 (2006) 155-164.

[6] P.N. Goudreau, A.M. Stock, Signal transduction in bacteria: molecular mechanisms of stimulus-response coupling, Curr. Opin. Microbiol. 1 (1998) 160-169.

[7] V.L. Robinson, D.R. Buckler, A.M. Stock, A tale of two components: a novel kinase and a regulatory switch, Nat. Struct. Biol. 7 (2000) 626-633.

[8] C.M. Fraser, J.D. Gocayne, O. White, M.D. Adams, R.A. Clayton, R.D. Fleischmann, C.J. Bult, A.R. Kerlavage, G. Sutton, J.M. Kelley, R.D. Fritchman, J.F. Weidman, K.V. Small, M. Sandusky, J. Fuhrmann, D. Nguyen, T.R. Utterback, D.M. Saudek, C.A. Phillips, J.M. Merrick, J.F. Tomb, B.A. Dougherty, K.F. Bott, P.C. Hu, T.S. Lucier, S.N. Peterson, H. O. Smith, C.A. Hutchison III, J.C. Venter, The minimal gene complement of Mycoplasma genitalium, Science 270 (1995) 397-403.

[9] R. Himmelreich, H. Hilbert, H. Plagens, E. Pirkl, B.C. Li, R. Herrmann, Complete sequence analysis of the genome of the bacterium Mycoplasma pneumoniae, Nucl. Acids Res. 24 (1996) 4420-4449. 
[10] T. Mizuno, T. Kaneko, S. Tabata, Compilation of all genes encoding bacterial two-component signal transducers in the genome of the cyanobacterium, Synechocystis sp. strain PCC 6803, DNA Res. 3 (1996) 407-414.

[11] T. Parish, D.A. Smith, S. Kendall, N. Casali, G.J. Bancroft, N.G. Stoker, Deletion of two-component regulatory systems increases the virulence of Mycobacterium tuberculosis, Infect. Immun. 71 (2003) 1134-1140.

[12] T. Parish, D.A. Smith, G. Roberts, J. Betts, N.G. Stoker, The senX3regX3 two-component regulatory system of Mycobacterium tuberculosis is required for virulence, Microbiology 149 (2003) 1423-1435.

[13] E. Perez, S. Samper, Y. Bordas, C. Guilhot, B. Giquel, C. Martin, An essential role for phoP in Mycobacterium tuberculosis virulence, Mol. Microbiol. 41 (2001) 179-187.

[14] L. Rickman, J.W. Saldanha, D.M. Hunt, D.N. Hoar, M.J. Colston, J.B. Millar, R.S. Buxton, A two-component signal transduction system with a PAS domain-containing sensor is required for virulence of Mycobacterium tuberculosis in mice, Biochem. Biophys. Res. Commun. 314 (2004) 259-267.

[15] T.C. Zahrt, V. Deretic, Mycobacterium tuberculosis signal transduction system required for persistent infections, Proc. Natl. Acad. Sci. U. S. A. 98 (2001) 12706-12711.

[16] T.C. Zahrt, V. Deretic, An essential two-component signal transduction system in Mycobacterium tuberculosis, J. Bacteriol. 182 (2000) 3832-3838.

[17] S.T. Cole, et al., Deciphering the biology of Mycobacterium tuberculosis from the complete genome sequence, Nature 393 (1998) 537-544.

[18] P.S. Fontan, S. Walters, I. Smith, Cellular signaling pathways and transcriptional regulation in Mycobacterium tuberculosis, Curr. Sci. 86 (2004) 122-134.

[19] Y. Av-Gay, V. Deretic, Two-component systems, protein kinases and signal transduction in Mycobacterium tuberculosis, in: S.T. Cole, K.D. Eisenach, D.N. McMurray, W.R. Jacobs Jr. (Eds.), Tuberculosis and the Tubercle Bacillus, ASM Press, Washington DC, 2005, pp. 359-367.

[20] A. Narayan, P. Sachdeva, K. Sharma, A.K. Saini, A.K. Tyagi, Y. Singh, Serine threonine protein kinases of mycobacterial genus: phylogeny to function, Physiol. Genomics 29 (2007) 66-75.

[21] S.K. Hanks, T. Hunter, Protein kinases 6. The eukaryotic protein kinase superfamily: kinase (catalytic) domain structure and classification, FASEB J. 9 (1995) 576-596.

[22] G. Manning, D.B. Whyte, R. Martinez, T. Hunter, S. Sudarsanam, The protein kinase complement of the human genome, Science 298 (2002) 1912-1934.

[23] M. Ortiz-Lombardia, F. Pompeo, B. Boitel, P.M. Alzari, Crystal structure of the catalytic domain of the PknB serine/threonine kinase from Mycobacterium tuberculosis, J. Biol. Chem. 278 (2003) 13094-13100.

[24] T.A. Young, B. Delagoutte, J.A. Endrizzi, A.M. Falick, T. Alber, Structure of Mycobacterium tuberculosis $\mathrm{PknB}$ supports a universal activation mechanism for Ser/Thr protein kinases, Nat. Struct. Biol. 10 (2003) 168-174.

[25] B. Boitel, M. Ortiz-Lombardia, R. Duran, F. Pompeo, S.T. Cole, C. Cerveñansky, P.M. Alzari, PknB kinase activity is regulated by phosphorylation in two Thr residues and dephosphorylation by PstP, the cognate phospho-Ser/Thr phosphatase, in Mycobacterium tuberculosis, Mol. Microbiol. 49 (2003) 1493-1508.

[26] A. Wehenkel, P. Fernandez, M. Bellinzoni, V. Catherinot, N. Barilone, G. Labesse, M. Jackson, P.M. Alzari, The structure of PknB in complex with mitoxantrone, an ATP-competitive inhibitor, suggests a mode of protein kinase regulation in mycobacteria, FEBS Lett. 580 (2006) 3018-3022.

[27] L.M. Gay, H.L. Ng, T. Alber, A conserved dimer and global conformational changes in the structure of apo-PknE Ser/Thr protein kinase from Mycobacterium tuberculosis, J. Mol. Biol. 360 (2006) 409-420.

[28] A.C. Dar, T.E. Dever, F. Sicheri, Higher-order substrate recognition of eIF2a by the RNA-dependent protein kinase PKR, Cell 122 (2005) 887-900.

[29] M. Dey, C. Cao, A.C. Dar, T. Tamura, K. Ozato, F. Sicheri, T.E. Dever, Mechanistic link between PKR dimerization, autophosphorylation, and eIF2alpha substrate recognition, Cell 122 (2005) 901-913.
[30] E. Madec, A. Laszkiewicz, A. Iwanicki, M. Obuchowski, S. Seror, Characterization of a membrane-linked Ser/Thr protein kinase in Bacillus subtilis, implicated in developmental processes, Mol. Microbiol. 46 (2002) 571-586.

[31] A.E. Greenstein, N. Echols, T.N. Lombana, D.S. King, T. Alber, Allosteric activation by dimerization of the $\mathrm{PknD}$ receptor Ser/Thr protein kinase from Mycobacterium tuberculosis, J. Biol. Chem. 282 (2007) 11427-11435.

[32] M.C. Good, A.E. Greenstein, T.A. Young, H.-L. Ng, T. Alber, Sensor domain of the Mycobacterium tuberculosis receptor Ser/Thr protein kinase, PknD, forms a highly symmetric b propeller, J. Mol. Biol. 339 (2004) 459-469.

[33] C. Yeats, R.D. Finn, A. Bateman, The PASTA domain: a b-lactambinding domain, Trends Biochem. Sci. 27 (2002) 438-440.

[34] E. Gordon, N. Mouz, E. Duee, O. Dideberg, The crystal structure of the penicillin-binding protein $2 \mathrm{x}$ from Streptococcus pneumoniae and its acyl-enzyme form: implication in drug resistance, J. Mol. Biol. 299 (2000) 477-485.

[35] G. Jones, P. Dyson, Evolution of transmembrane protein kinase implicated in coordinating remodelling of Gram-positive peptidoglycan: inside versus outside, J. Bacteriol. 188 (2006) 7470-7476.

[36] N.H. Keep, J.M. Ward, M. Cohen-Gonsaud, B. Henderson, Wake up! Peptidoglycan lysis and bacterial non-growth states, Trends Microbiol. 14 (2006) 271-276.

[37] M.D. Jackson, J.M. Denu, Molecular reactions of protein phosphatases insights from structure and chemistry, Chem. Rev. 101 (2001) 2313-2340.

[38] P. Chopra, B. Singh, R. Singh, R. Vohra, A. Koul, L.S. Meena, H. Koduri, M. Ghildiyal, P. Deol, T.K. Das, A.K. Tyagi, Y. Singh, Phosphoprotein phosphatase of Mycobacterium tuberculosis dephosphorylates serinethreonine kinases PknA and PknB, Biochem. Biophys. Res. Commun. 311 (2003) 112-120.

[39] R. Duran, A. Villarino, M. Bellinzoni, A. Wehenkel, P. Fernandez, B. Boitel, S.T. Cole, P.M. Alzari, C. Cerveñansky, Conserved autophosphorylation pattern in activation loops and juxtamembrane regions of Mycobacterium tuberculosis Ser/Thr protein kinases, Biochem. Biophys. Res. Commun. 333 (2005) 858-867.

[40] K.E. Pullen, H.L. Ng, P.Y. Sung, M.C. Good, S.M. Smith, T. Alber, An alternate conformation and a third metal in PstP/Ppp, the M. tuberculosis PP2C-Family Ser/Thr protein phosphatase, Structure 12 (2004) 1947-1954.

[41] M. Bellinzoni, A. Wehenkel, W. Shepard, P.M. Alzari, Insights into the catalytic mechanism of PPM Ser/Thr phosphatases from the atomic resolution structures of a mycobacterial enzyme, Structure 15 (2007) $863-872$.

[42] A.K. Das, N.R. Helps, P.T. Cohen, D. Barford, Crystal structure of the protein serine/threonine phosphatase $2 \mathrm{C}$ at $2.0 \AA$ Å resolution, EMBO J. 15 (1996) 6798-6809.

[43] M.K. Rantanen, L. Lehtio, L. Rajagopal, C.E. Rubens, A. Goldman, Structure of Streptococcus agalactiae serine/threonine phosphatase. The subdomain conformation is coupled to the binding of a third metal ion, FEBS J. 274 (2007) 3128-3137.

[44] A. Koul, A. Choidas, M. Treder, A.K. Tyagi, K. Drlica, Y. Singh, A. Ullrich, Cloning and characterization of secretory tyrosine phosphatases of Mycobacterium tuberculosis, J. Bacteriol. 182 (2000) 5425-5432.

[45] A. Koul, T. Herget, B. Klebl, A. Ullrich, Interplay between mycobacteria and host signalling pathways, Nat. Rev. 2 (2004) 189-202.

[46] C. Madhurantakam, E. Rajakumara, P.A. Mazumdar, B. Saha, D. Mitra, H.G. Wiker, R. Sankaranarayanan, A.K. Das, Crystal structure of lowmolecular-weight protein tyrosine phosphatase from Mycobacterium tuberculosis at $1.9 \AA$ resolution, J. Bacteriol. 187 (2005) 2175-2181.

[47] C. Grundner, H.-L. Ng, T. Alber, Mycobacterium tuberculosis protein tyrosine phosphatase PtpB structure reveals a diverged fold and a buried active site, Structure 13 (2005) 1625-1634.

[48] N. Beresford, S. Patel, J. Armstrong, B. Szoor, A.P. Fordham-Skelton, L. Tabernero, MptpB, a virulence factor from Mycobacterium tuberculosis exhibits triple-specificity phosphatase activity, Biochem. J. 406 (2007) 13-18.

[49] R. Singh, V. Rao, H. Shaklla, R. Gupta, A. Khera, N. Dhar, A. Singh, A. 
Koul, Y. Singh, M. Naseerna, P.R. Narayanan, C.N. Paramaslvan, V.D. Ramanathan, A.K. Tyagl, Disruption of mptpB impairs the ability of Mycobacterium tuberculosis to survive in guinea pigs, Mol. Microbiol. 50 (2003) 751-762.

[50] C. Grundner, D. Perrin, R. Hooft van Huijsduijnen, D. Swinnen, J. Gonzalez, C.L. Gee, T.N. Wells, T. Alber, Structural basis for selective inhibition of Mycobacterium tuberculosis protein tyrosine phosphatase PtpB, Structure 15 (2007) 499-509.

[51] S.T. Cole, K. Eiglmeier, J. Parkhill, K.D. James, N.R. Thomson, P.R. Wheeler, N. Honore, T. Garnier, C. Churcher, D. Harris, K. Mungall, D. Basham, D. Brown, T. Chillingworth, R. Connor, R.M. Davies, K. Devlin, S. Duthoy, T. Feltwell, A. Fraser, N. Hamlin, S. Holroyd, T. Hornsby, K. Jagels, C. Lacroix, J. Maclean, S. Moule, L. Murphy, K. Oliver, M.A. Quail, M.A. Rajandream, K.M. Rutherford, S. Rutter, K. Seeger, S. Simon, M. Simmonds, J. Skelton, R. Squares, S. Squares, K. Stevens, K. Taylor, S. Whitehead, J.R. Woodward, B.G. Barrell, Massive gene decay in the leprosy bacillus, Nature 409 (2001) 1007-1011.

[52] C.M. Sassetti, D.H. Boyd, E.J. Rubin, Genes required for mycobacterial growth defined by high density mutagenesis, Mol. Microbiol. 48 (2003) $77-84$.

[53] C.M. Sassetti, E.J. Rubin, Genetic requirements for mycobacterial survival during infection, Proc. Natl. Acad. Sci. U. S. A. 100 (2003) 12989-12994.

[54] P. Fernandez, B. Saint-Joanis, N. Barilone, M. Jackson, B. Gicquel, S.T. Cole, P.M. Alzari, The Ser/Thr protein kinase PknB is essential for sustaining mycobacterial growth, J. Bacteriol. 188 (2006) 7778-7784.

[55] K.G. Papavinasasundaram, B. Chan, J.-H. Chung, M.J. Colston, E.O. Davis, Y. Av-Gay, Deletion of the Mycobacterium tuberculosis pknH gene confers a higher bacillary load during the chronic phase of infection in the BalB/c mice, J. Bacteriol. 187 (2005) 5751-5760.

[56] J. Perez, R. Garcia, H. Bach, J.H. de Waard, W.R. Jacobs Jr., Y. Av-Gay, J. Bubis, H.E. Takiff, Mycobacterium tuberculosis transporter MmpL7 is a potential substrate for kinase PknD, Biochem. Biophys. Res. Commun. 348 (2006) 6-12.

[57] P. Deol, R. Vohra, A.K. Saini, A. Singh, H. Chandra, P. Chopra, T.K. Das, A.K. Tyagi, Y. Singh, Role of Mycobacterium tuberculosis Ser/Thr kinase PknF: implications in glucose transport and cell division, J. Bacteriol. 187 (2005) 3415-3420.

[58] J.M. Curry, R. Whalan, D.M. Hunt, K. Gohil, M. Strom, L. Rickman, M.J. Colston, S.J. Smerdon, R.S. Buxton, An ABC transporter containing a forkhead-associated domain interacts with a serine-threonine protein kinase and is required for growth of Mycobacterium tuberculosis in mice, Infect. Immun. 73 (2005) 4471-4477.

[59] V. Molle, D. Soulat, J.-M. Jault, C. Grangeasse, A.J. Cozzone, J.-F. Prost, The two FHA domains on an $\mathrm{ABC}$ transporter, Rv1747, mediate its phosphorylation by $\mathrm{PknF}$, a Ser/Thr protein kinase from Mycobacterium tuberculosis, FEMS Microbiol. Lett. 234 (2004) 215-223.

[60] S. Cowley, M. Ko, N. Pick, R. Chow, K.J. Downing, B.G. Gordhan, J.C. Betts, V. Mizrahi, D.A. Smith, R.W. Stokes, Y. Av-Gay, The Mycobacterium tuberculosis protein serine/threonine kinase PknG is linked to cellular glutamate/glutamine levels and is important for growth in vivo, Mol. Microbiol. 52 (2004) 1691-1702.

[61] L. Nguyen, A. Walburger, E. Houben, A. Koul, S. Muller, M. Morbitzer, B. Klebl, G. Ferrari, J. Pieters, Role of protein kinase G in growth and glutamine metabolism of Mycobacterium bovis BCG, J. Bacteriol. 187 (2005) 5852-5856.

[62] A. Niebisch, A. Kabus, C. Schultz, B. Weil, M. Bott, Corynebacterial protein kinase $\mathrm{G}$ controls 2-oxoglutarate dehydrogenase activity via the phosphorylation status of the OdhI protein, J. Biol. Chem. 281 (2006) 12300-12307.

[63] A. Walburger, A. Koul, G. Ferrari, L. Nguyen, C. Prescianotto-Baschong, K. Huygen, B. Klebl, C. Thompson, G. Bacher, J. Pieters, Protein kinase $\mathrm{G}$ from pathogenic mycobacteria promotes survival within macrophages, Science 304 (2004) 1800-1804.

[64] N. Scherr, S. Honnappa, G. Kunz, P. Mueller, R. Jayachandran, F. Winkler, J. Pieters, M.O. Steinmetz, Structural basis for the specific inhibition of protein kinase $\mathrm{G}$, a virulence factor of Mycobacterium tuberculosis, Proc. Natl. Acad. Sci. U. S. A. 104 (2007) 12151-12156.
[65] M. Matsuhashi, Utilization of lipid-linked precursors and the formation of peptidoglycan in the process of cell growth and division, in: J.-M. Ghuysen, R. Hakenbeck (Eds.), Bacterial Cell Wall, Elsevier, Amsterdam-London, 1994, pp. 55-71.

[66] A.O. Henriques, P. Glaser, P.J. Piggot, C.P. Moran Jr., Control of cell shape and elongation by the rodA gene in Bacillus subtilis, Mol. Microbiol. 28 (1998) 235-247.

[67] R. Del Sol, J.G.L. Mullins, N. Grantcharova, K. Flärdh, P. Dyson, Influence of $\mathrm{CrgA}$ on assembly of the cell division protein FtsZ during development of Streptomyces coelicolor, J. Bacteriol. 188 (2006) 1540-1550.

[68] C.M. Kang, D.W. Abbott, S.T. Park, C.C. Dascher, L.C. Cantley, R.N. Husson, The Mycobacterium tuberculosis serine/threonine kinases PknA and PknB: substrate identification and regulation of cell shape, Genes Dev. 19 (2005) 1692-1704.

[69] Y. Av-Gay, S. Jamil, S.J. Drews, Expression and characterization of the Mycobacterium tuberculosis serine/threonine protein kinase PknB, Infect. Immun. 67 (1999) 5676-5682.

[70] A. Singh, Y. Singh, R. Pine, L. Shi, R. Chandra, K. Drlica, Protein kinase I of Mycobacterium tuberculosis: cellular localization and expression during infection of macrophage-like cells, Tuberculosis 86 (2006) 28-33.

[71] J.C. Betts, P.T. Lukey, L.C. Robb, R.A. McAdam, K. Duncan, Evaluation of a nutrient starvation model of Mycobacterium tuberculosis persistence by gene and protein expression profiling, Mol. Microbiol. 43 (2002) $717-731$.

[72] R. Chaba, M. Raje, P.K. Chakraborti, Evidence that a eukaryotic-type serine/threonine protein kinase from Mycobacterium tuberculosis regulates morphological changes associated with cell division, Eur. J. Biochem. 269 (2002) 1078-1085.

[73] M. Thakur, P.K. Chakraborti, GTPase Activity of mycobacterial FtsZ is impaired due to its transphosphorylation by eukaryotic-type Ser/Thr kinase, PknA, J. Biol. Chem. 281 (2006) 40107-40113.

[74] C.J. Kristich, C.L. Wells, G.M. Dunny, A eukaryotic-type Ser/Thr kinase in Enterococcus faecalis mediates antimicrobial resistance and intestinal persistence, Proc. Natl. Acad. Sci. U. S. A. 104 (2007) 3508-3513.

[75] A.K. Bendt, A. Burkovski, S. Schaffer, M. Bott, M. Farwick, T. Hermann, Towards a phosphoproteome map of Corynebacterium glutamicum, Proteomics 3 (2003) 1637-1646.

[76] A. Levine, F. Vannier, C. Absalon, L. Kuhn, P. Jackson, E. Scrivener, V. Labas, J. Vinh, P. Courtney, J. Garin, S.J. Seror, Analysis of the dynamic Bacillus subtilis $\mathrm{Ser} / \mathrm{Thr} / \mathrm{Tyr}$ phosphoproteome implicated in a wide variety of cellular processes, Proteomics 6 (2006) 2157-2173.

[77] B. Macek, I. Mijakovic, J.V. Olsen, F. Gnad, C. Kumar, P.R. Jensen, M. Mann, The serine/threonine/tyrosine phosphoproteome of the model bacterium Bacillus subtilis, Mol. Cell. Proteomics 6 (2007) 697-707.

[78] P. Peirs, L. De Wit, M. Braibant, K. Huygen, J. Content, A serine/ threonine protein kinase from Mycobacterium tuberculosis, Eur. J. Biochem. 244 (1997) 604-612.

[79] A. Koul, A. Choidas, A.K. Tyagi, K. Drlica, Y. Singh, A. Ullrich, Serine/ threonine protein kinases PknF and PknG of Mycobacterium tuberculosis: characterization and localization, Microbiology 147 (2001) 2307-2314.

[80] V. Molle, C. Girard-Blanc, L. Kremer, P. Doublet, A.J. Cozzone, J.F. Prost, Protein PknE, a novel transmembrane eukaryotic-like serine/ threonine kinase from Mycobacterium tuberculosis, Biochem. Biophys. Res. Commun. 308 (2003) 820-825.

[81] V. Molle, L. Kremer, C. Girard-Blanc, G.S. Besra, A.J. Cozzone, J.F. Prost, An FHA phosphoprotein recognition domain mediates protein EmbR phosphorylation by $\mathrm{PknH}$, a Ser/Thr protein kinase from Mycobacterium tuberculosis, Biochemistry 42 (2003) 15300-15309.

[82] R. Gopalaswamy, P.R. Narayanan, S. Narayanan, Cloning, overexpression, and characterization of a serine/threonine protein kinase $\mathrm{pknI}$ from Mycobacterium tuberculosis H37Rv, Prot. Expr. Purif. 36 (2004) 82-89.

[83] D.C. Berwick, J.M. Tavaré, Identifying protein kinase substrates: hunting for the organgrinder's monkey, Trends Biochem. Sci. 29 (2004) 227-232.

[84] V. Molle, I. Zanella-Cleon, J.P. Robin, S. Mallejac, A.J. Cozzone, M. Becchi, Characterization of the phosphorylation sites of Mycobacterium tuberculosis serine/threonine protein kinases, PknA, PknD, PknE, and PknH by mass spectrometry, Proteomics 6 (2006) 3754-3766.

[85] E. Madec, A. Stensballe, S. Kjellstrom, L. Cladiere, M. Obuchowski, O.N. 
Jensen, S.J. Seror, Mass spectrometry and site-directed mutagenesis identify several autophosphorylated residues required for the activity of PrkC, a Ser/Thr kinase from Bacillus subtilis, J. Mol. Biol. 330 (2003) 459-472.

[86] A. Dasgupta, P. Datta, M. Kundu, J. Basu, The serine/threonine kinase PknB of Mycobacterium tuberculosis phosphorylates PBPA, a penicillinbinding protein required for cell division, Microbiology 152 (2006) 493-504.

[87] D. Durocher, J. Henckel, A.R. Fersht, S.P. Jackson, The FHA domain is a modular phosphopeptide recognition motif, Mol. Cell 4 (1999) 387-394.

[88] D. Durocher, S.P. Jackson, The FHA domain, FEBS Lett. 513 (2002) $58-66$.

[89] M.B. Yaffe, S.J. Smerdon, PhosphoSerine/threonine binding domains: you can't pSERious? Structure 9 (2001) R33-R38.

[90] L.J. Alderwick, V. Molle, L. Kremer, A.J. Cozzone, T.R. Dafforn, G.S. Besra, K. Futterer, Molecular structure of EmbR, a response element of Ser/Thr kinase signaling in Mycobacterium tuberculosis, Proc. Natl. Acad. Sci. U. S. A. 103 (2006) 2558-2563.

[91] C. Grundner, L.M. Gay, T. Alber, Mycobacterium tuberculosis serine/ threonine kinases PknB, PknD, PknE, and PknF phosphorylate multiple FHA domains, Protein Sci. 14 (2005) 1918-1921.

[92] A. Villarino, R. Duran, A. Wehenkel, P. Fernandez, P. England, P. Brodin, S.T. Cole, U. Zimny-Arndt, P.R. Jungblut, C. Cerveñansky, P.M. Alzari, Proteomic identification of $M$. tuberculosis protein kinase substrates: PknB recruits GarA, a FHA domain-containing protein, through activation loop-mediated interactions, J. Mol. Biol. 350 (2005) 953-963.
[93] K. Sharma, M. Gupta, A. Krupa, N. Srinivasan, Y. Singh, EmbR, a regulatory protein with ATPase activity, is a substrate of multiple serine/ threonine kinases and phosphatase in Mycobacterium tuberculosis, FEBS J. 273 (2006) 2711-2721.

[94] V. Molle, A.K. Brown, G.S. Besra, A.J. Cozzone, L. Kremer, The condensing activities of the Mycobacterium tuberculosis Type II fatty acid synthase are differentially regulated by phosphorylation, J. Biol. Chem. 281 (2006) 30094-30103.

[95] A.E. Greenstein, J.A. MacGurn, C.E. Baer, A.M. Falick, J.S. Cox, T. Alber, M. tuberculosis Ser/Thr protein kinase D phosphorylates an antianti-sigma factor homolog, PLoS Pathog. 3 (2007) e49, doi: 10.1371/ journal.ppat.0030049.

[96] A.E. Belanger, G.F. Hatfull, Exponential-phase glycogen recycling is essential for growth of Mycobacterium smegmatis, J. Bacteriol. 181 (1999) 6670-6678.

[97] R.M. Biondi, A.R. Nebreda, Signalling specificity of Ser/Thr protein kinases through docking-site-mediated interactions, Biochem. J. 372 (2003) $1-13$.

[98] J. Hu, J. Liu, R. Ghirlando, A.R. Saltie, S.R. Hubbard, Structural basis for recruitment of the adaptor protein APS to the activated insulin receptor, Mol. Cell 12 (2003) 1379-1389.

[99] R. Capdeville, E. Buchdunger, J. Zimmermann, A. Matter, Glivec (STI571, imatinib), a rationally developed, targeted anticancer drug, Nat. Rev. Drug Discov. 1 (2002) 493-502.

[100] R. Durbin, S.R. Eddy, A. Krogh, G.J. Mitchison, Biological Sequence Analysis: Probabilistic Models of Proteins and Nucleic Acids, Cambridge University Press, Cambridge UK, 1998. 